\title{
Analysis about Influence of Dry Anaerobic Fermentation on Main Nutrients of Biogas Residue
}

\author{
Wang Shuo, Jiao Jing*, Li Zunxiang, Huang Xiaohong, Du Jihua, Wang Jinli, \\ Guo Changjin
}

\author{
Institute of Agricultural Machinery, Chinese Academy of Tropical Agricultural Sciences
}

(CATAS),Zhanjiang 524091, Guangdong, P.R. China

wangshuo3564@126.com, eddweiss@163.com, 1192187600@qq.com

\begin{abstract}
Key words: Dry anaerobic fermentation; biogas residue; comprehensive indicator; multivariant linear regression

Abstract. In order to boost the use value of biogas residue, main factors in dry fermentation were chosen to design an experiment to observe nutrient changes under different conditions before and after dry fermentation. The effects of manure-crop ratio, inoculum size, dry matter concentration and fermentation temperature on main nutrients before and after anaerobic fermentation were studied in this paper. Multivariant linear analysis of two comprehensive indicators shows that pretreatment has a significant effect on the increase in the content of rapidly available phosphorus and rapidly available potassium; manure-crop ratio shows a significant effect on the rise of organic content; the influence of other factors is not significant
\end{abstract}

\section{Introduction}

Biogas residue is made by composting the residues after dry anaerobic fermentation of sugarcane leaves and pig manure. It is rich in organic matters and essential nutrients, so it is a good bio-organic fertilizer. The methane is fermented slowly, and the consumption of organic matters is low. Besides, the loss of nitrogen, phosphorus and potassium is small. The recovery rate of nitrogen can reach $95 \%$, and recovery rate of kalium exceeds $90 \%$. Biogas residue can be used a few days later after the fermentation. In the previous experiments, sugarcane leave biogas residue plays an obvious promotion role for dragon fruit, hot pepper and okra etc.

To further improve the position of biogas residue among organic fertilizers, the effects of manure-crop ratio, inoculum size, dry matter concentration and fermentation temperature on main nutrients before and after anaerobic fermentation were studied through single-factor experiment in this paper. Through regression analysis of experimental data, the optimal fermentation process parameters have been found out.

\section{Materials and method}

Experimental materials and devices. Raw materials: dry and yellow sugarcane leaves from the sugarcane field around Zhanjiang Huguang Farm, which were smashed to $2-5 \mathrm{~cm}$ irregular chippings with a pulverizer, with the total solid mass fraction of $87 \%$; pig manure from an individual pig breeder near Gaoyang, Zhanjiang, with the total solid mass fraction of $25 \%$.

Inoculum: enriched materials from moderate-temperature and dry anaerobic fermentation of sugarcane leaves and pig manure. The enrichment time is greater than 2 months, and the total solid mass fraction is $20 \%$.

Experiment design and method. The following experiment program was designed to explore main technological parameters of anaerobic fermentation of sugarcane leaves and their influence on biogas residue and confirm the optimal technological parameters through single factor analysis and regression analysis. 5 factors and 4 levels were chosen. In the single factor experiment, other factors 
were fixed at the optimal level gained from the feasibility experiment in the early stage. Before and after the anaerobic fermentation, samples were taken to measure the content of moisture, nitrogen, phosphorus, potassium and organic matters. After the experiment started, the temperature in the fermentation tank, daily gas output and methane content (may be measured at the time interval of 2-3d) were measured every day.

Table 1 Experiment program

\begin{tabular}{cccccc}
\hline Observation & Pretreatment/h & $\begin{array}{c}\text { Manure-cr } \\
\text { op ratio }\end{array}$ & $\begin{array}{c}\text { Inoculum } \\
\text { size kg }\end{array}$ & $\begin{array}{c}\text { Dry matter } \\
\text { concentration } \%\end{array}$ & $\begin{array}{c}\text { Fermentation } \\
\text { temperature }{ }^{\circ} \mathrm{C}\end{array}$ \\
\hline 1 & 11.90 & 1.00 & 3.50 & 20.00 & 38.00 \\
2 & 12.00 & 1.00 & 3.50 & 20.00 & 38.00 \\
3 & 48.00 & 1.00 & 3.50 & 20.00 & 38.00 \\
4 & 84.00 & 1.00 & 3.50 & 20.00 & 38.00 \\
5 & 12.00 & 0.00 & 3.50 & 20.00 & 38.00 \\
6 & 12.00 & 0.50 & 3.50 & 20.00 & 38.00 \\
7 & 12.00 & 1.00 & 3.50 & 20.00 & 38.00 \\
8 & 12.00 & 2.00 & 3.50 & 20.00 & 38.00 \\
9 & 12.00 & 2.00 & 2.30 & 20.00 & 38.00 \\
10 & 12.00 & 2.00 & 3.50 & 20.00 & 38.00 \\
11 & 12.00 & 2.00 & 4.60 & 20.00 & 38.00 \\
12 & 12.00 & 2.00 & 5.80 & 20.00 & 38.00 \\
13 & 12.00 & 2.00 & 5.80 & 15.00 & 38.00 \\
14 & 12.00 & 2.00 & 5.80 & 20.00 & 38.00 \\
15 & 12.00 & 2.00 & 5.80 & 25.00 & 38.00 \\
16 & 12.00 & 2.00 & 5.80 & 30.00 & 38.00 \\
17 & 12.00 & 2.00 & 5.80 & 20.00 & 25.00 \\
18 & 12.00 & 2.00 & 5.80 & 20.00 & 35.00 \\
19 & 12.00 & 2.00 & 5.80 & 20.00 & 37.50 \\
20 & 12.00 & 2.00 & 5.80 & 20.00 & 40.00 \\
\hline
\end{tabular}

Note: level of factor pretreatment $=0.5 \mathrm{x}$ wetting time of sugarcane leaves $+0.5 \mathrm{x}$ composting time. In the formula, the unit of each variable is hour.

\section{Results and analyses}

Nutrient increment characteristics before and after fermentation. The difference between nutrient measurement results before and after the fermentation is called nutrient increment. 20 observations gained from the experiment show that the content of total nitrogen and rapidly available nitrogen changes little; the content of organic matters both decreases and increases, but the decrease is dominated; the content of rapidly available phosphorus and rapidly available potassium rises, and the increase range of rapidly available phosphorus is greater than that of rapidly available potassium in most observations, as shown in Fig.1. 


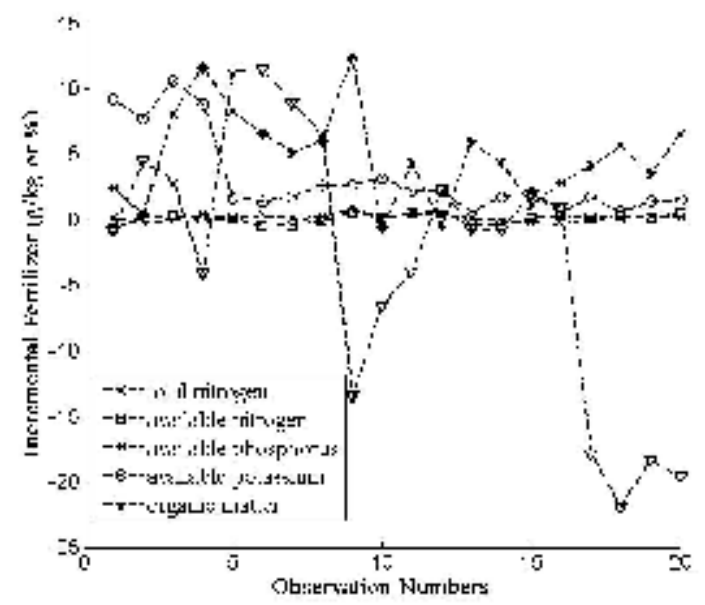

Fig.1 Nutrient increment characteristics of biogas residue before and after fermentation

Nutrient increment synthesis before and after fermentation. Since it was not easy to clearly see the change rules through observing the 5 nutrient increment indicators, principal component analysis was used to synthesize 5 nutrient increment indicators into 2 comprehensive indicators.

Table 2 Characteristics of nutrient increment comprehensive indicators CI

\begin{tabular}{ccccc}
\hline $\mathrm{CI}$ & Variance & $\begin{array}{c}\text { Variance } \\
\text { increment }\end{array}$ & Variance ratio & $\begin{array}{c}\text { Accumulative } \\
\text { variance ratio }\end{array}$ \\
\hline $\mathrm{CI}_{1}$ & 108.3442 & 95.1481 & 0.8310 & 0.8310 \\
$\mathrm{CI}_{2}$ & 13.1961 & 4.5363 & 0.1012 & 0.9322 \\
$\mathrm{CI}_{3}$ & 8.6598 & 8.5356 & 0.0664 & 0.9987 \\
$\mathrm{CI}_{4}$ & 0.1243 & 0.0752 & 0.0010 & 0.9996 \\
$\mathrm{CI}_{5}$ & 0.0490 & & 0.0004 & 1.0000 \\
\hline
\end{tabular}

As shown in Table 2, variance ratio of the first comprehensive indicator $\mathrm{CI}_{1}$ (the first principal component) is as high as $83.10 \%$, while variance ratio of the second comprehensive indicator $\mathrm{CI}_{2}$ (the second principal component) reaches $10.12 \%$. The accumulative variance ratio is $93.22 \%$. Thus, the two indicators are needed to discuss the characteristics of nutrient increment.

Table 3 Structure mode of nutrient increment comprehensive indicators CI

\begin{tabular}{ccc}
\hline Nutrient increment & $\mathrm{CI}_{1}$ & $\mathrm{CI}_{2}$ \\
\hline Total nitrogen $\left(\mathrm{y}_{1}\right)$ & -0.0069 & 0.0344 \\
Rapidly available nitrogen $\left(\mathrm{y}_{2}\right)$ & -0.0161 & 0.0009 \\
Rapidly available phosphorus $\left(\mathrm{y}_{3}\right)$ & -0.0332 & 0.9216 \\
Rapidly available potassium $\left(\mathrm{y}_{4}\right)$ & 0.0619 & 0.3866 \\
organic matter $\left(\mathrm{y}_{5}\right)$ & 0.9974 & 0.0069
\end{tabular}

As shown in Table $3, \mathrm{CI}_{1}$ mainly represents the increment of organic matters before and after the

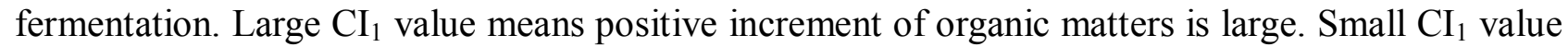
means positive increment of organic matters is small and even the increment is negative.

As shown in Table $3, \mathrm{CI}_{2}$ mainly represents the increment of rapidly available phosphorus and rapidly available potassium before and after the fermentation. The ratio of rapidly available phosphorus is about 2.4 times of that of rapidly available potassium. $\mathrm{Large} \mathrm{CI}_{2}$ value means positive increment of rapidly available phosphorus and rapidly available potassium is large (especially rapidly available phosphorus). Small $\mathrm{CI}_{2}$ value means positive increment of rapidly available phosphorus and rapidly available potassium is small and even the increment is negative. 
Computational formulas of $\mathrm{CI}_{1}$ and $\mathrm{CI}_{2}$ are as follows:

$$
\begin{aligned}
& \mathrm{CI}_{1}=-0.0069 y_{1}-0.0161 y_{2}-0.0332 y_{3}+0.0619 y_{4}+0.9974 y_{5} \\
& \mathrm{CI}_{2}=0.0344 y_{1}+0.0009 y_{2}+0.9216 y_{3}+0.3866 y_{4}+0.0069 y_{5}
\end{aligned}
$$

Optimal parameters for fermentation technology. The values of $\mathrm{CI}_{1}$ and $\mathrm{CI}_{2}$ in the 20 experiments were figured out. Then, the values are sorted according to $\mathrm{CI}_{1}$ in ascending order. The results are shown in Table 4.

Table $4 \mathrm{CI}$ and ranking in the 20 experiments

\begin{tabular}{cccccccc}
\hline $\begin{array}{c}\text { Observati } \\
\text { on }\end{array}$ & $\begin{array}{c}\text { Pretreatm } \\
\text { ent }\end{array}$ & $\begin{array}{c}\text { Manure } \\
\text {-crop } \\
\text { ratio }\end{array}$ & $\begin{array}{c}\text { Inoculu } \\
\text { m size }\end{array}$ & $\begin{array}{c}\text { Dry } \\
\text { matter }\end{array}$ & $\begin{array}{c}\text { Fermentati } \\
\text { on } \\
\text { temperatur } \\
\text { e }\end{array}$ & CI $_{1}$ & CI $_{2}$ \\
\hline 18 & 12 & 2 & 5.8 & 20 & 35 & -22.0768 & 5.3342 \\
20 & 12 & 2 & 5.8 & 20 & 40 & -19.7081 & 6.4872 \\
19 & 12 & 2 & 5.8 & 20 & 37.5 & -18.3073 & 3.7259 \\
17 & 12 & 2 & 5.8 & 20 & 25 & -17.8262 & 4.3902 \\
9 & 12 & 2 & 2.3 & 20 & 38 & -13.6981 & 12.4633 \\
10 & 12 & 2 & 3.5 & 20 & 38 & -6.2992 & 0.6770 \\
11 & 12 & 2 & 4.6 & 20 & 38 & -3.9310 & 4.8614 \\
4 & 84 & 1 & 3.5 & 20 & 38 & -3.8613 & 14.1546 \\
13 & 12 & 2 & 5.8 & 15 & 38 & -0.8112 & 5.7194 \\
14 & 12 & 2 & 5.8 & 20 & 38 & -0.7767 & 4.6870 \\
1 & 11.9 & 1 & 3.5 & 20 & 38 & -0.2672 & 5.7463 \\
16 & 12 & 2 & 5.8 & 30 & 38 & 0.9274 & 2.8271 \\
15 & 12 & 2 & 5.8 & 25 & 38 & 2.0727 & 1.9000 \\
12 & 12 & 2 & 5.8 & 20 & 38 & 2.4595 & 0.4336 \\
3 & 48 & 1 & 3.5 & 20 & 38 & 3.4526 & 11.6463 \\
2 & 12 & 1 & 3.5 & 20 & 38 & 4.9796 & 3.4132 \\
8 & 12 & 2 & 3.5 & 20 & 38 & 6.5672 & 6.6495 \\
7 & 12 & 1 & 3.5 & 20 & 38 & 8.8507 & 5.5312 \\
5 & 12 & 0 & 3.5 & 20 & 38 & 11.2566 & 8.4072 \\
6 & 12 & 0.5 & 3.5 & 20 & 38 & 11.3752 & 6.7296 \\
\hline
\end{tabular}

As shown in Table 4 , in the 20 observations, there are many negative values of $\mathrm{CI}_{1}$, while there are a few positive values. Besides, the absolute values of negative values are also large. This means the content of organic matters usually decreases after the fermentation. The values of $\mathrm{CI}_{2}$ are positive, which indicates the content of both rapidly available phosphorus and rapidly available potassium increases after the fermentation. The content of total nitrogen and rapidly available nitrogen changes little after the fermentation. Thus, nutrients of biogas residue mainly contain rapidly available phosphorus and rapidly available potassium after the fermentation.

In conclusion, the larger, the better for the content of rapidly available phosphorus, rapidly available potassium and organic matters in biogas residue after the fermentation. Based on this standard, the optimal parameters of fermentation technology were sought. In accordance with Table 8 , the three groups of observations with the contents of observation number, $\mathrm{CI}_{1}$ and $\mathrm{CI}_{2}$ $(3,3.4526,11.6463),(5,11.2566,8.4072)$ and $(6,11.3752,6.7296)$ are superior to other observations. The parameters of fermentation technology corresponding to No.3 observation are as follows: (wetting for $24 \mathrm{~h}+$ composting for $3 \mathrm{~d}$, manure-crop ratio $1: 1$, inoculum size 3.5 , dry matter concentration 20 and fermentation temperature $38^{\circ} \mathrm{C}$ ). The parameters of fermentation technology corresponding to No.5 observation are as follows: (wetting for $24 \mathrm{~h}+$ composting for 0d, manure-crop ratio 0:1, inoculum size 3.5, dry matter concentration 20 and fermentation temperature $38^{\circ} \mathrm{C}$ ). The parameters of fermentation technology corresponding to No.6 observation are as follows: 
(wetting for $24 \mathrm{~h}+$ composting for $0 \mathrm{~d}$, manure-crop ratio 1:2, inoculum size 3.5 , dry matter concentration 20 and fermentation temperature $38^{\circ} \mathrm{C}$ ). The optimal parameters of fermentation technology can be chosen from one of the above 3 experiments.

\section{Conclusion}

Principal component analysis and regression analysis were made for the increment of 5 nutrients after and before dry anaerobic fermentation. The results show that,

The content change of total nitrogen and rapidly available nitrogen is not significant. The content of organic matters decreases significantly. The content of rapidly available phosphorus and rapidly available potassium rises significantly, and the growing range of rapidly available phosphorus is generally greater than that of rapidly available potassium.

3 groups of relatively excellent parameters are gained, i.e. (wetting sugarcane leaves for $24 \mathrm{~h}+$ composting for $3 \mathrm{~d}$, manure-crop ratio $1: 1$, inoculum size $3.5 \mathrm{~kg}$, dry matter concentration $20 \%$ and fermentation temperature $38^{\circ} \mathrm{C}$ ), (wetting sugarcane leaves for $24 \mathrm{~h}+$ composting for $0 \mathrm{~d}$, manure-crop ratio $0: 1$, inoculum size $3.5 \mathrm{~kg}$, dry matter concentration $20 \%$ and fermentation temperature $38^{\circ} \mathrm{C}$ ) and (wetting sugarcane leaves for $24 \mathrm{~h}+$ composting for $0 \mathrm{~d}$, manure-crop ratio $1: 2$, inoculum size $3.5 \mathrm{~kg}$, dry matter concentration $20 \%$ and fermentation temperature $38^{\circ} \mathrm{C}$ ). The content of rapidly available phosphorus, rapidly available potassium and organic matters in biogas residue can increase significantly through using the three groups of technological parameters. Further experiment and exploration are still required to seek the optimal technological parameters.

\section{Acknowledgements}

This research is supported by Hainan Natural Science Fund (20163116) and(20155213) .

\section{References}

[1] Zheng Yong, Wang Jinli, Li Ming et al. Current Situation and Analysis of Resource Utilization of Tropical Agricultural Wastes - Comprehensive Utilization of Sugarcane Wastes[J]. Guangdong Agricultural Sciences, Vol.38 (1), p.15-18, 26 (2011).

[2] Jiao Jing, Wang Jinli, Deng Yiguo et al. Tropical Agricultural Waste Resources and Use of Biogas [J]. Journal of Anhui Agricultural Sciences,Vol.36 (30), p.13360-14451, 13405(2008).

[3] Jiao Jing, Wang Jinli, Deng Yiguo et al. Effect of ratios of manure to straw on sugarcane leaves dry anaerobic fermentation for biogas production [J]. Guangdong Agricultural Sciences, Vol.37 (1), p.51-54(2010).

[4] Wang Jinli, Jiao Jing, Zhang Jing et al. Sugarcane Leaves Dry Anaerobic Fermentation [J]. Transactions of the Chinese Society for Agricultural Machinery,Vol. 42 (3), p.109-114(2011). 